\title{
ESTIMATING THE ATMOSPHERIC INPUT OF POLLUTANTS INTO A WATERSHED
}

\author{
PERRY J, SAMSON \\ Department of Atmospheric and Oceanic Science, University of Michigan, Ann Arbor, MI 48109-2143, \\ U.S.A.
}

(Received June 20, 1986; revised March 11, 1987)

\begin{abstract}
Estimating the atmospheric input of ions to a watershed has traditionally been accomplished through either the extrapolation of point measurements of deposition or the integration of model estimated deposition. This paper examines the characteristics of precipitation chemistry on the eastern seaboard of the United States where precipitation quality could conceivably affect fish habitats in estuaries. The measured values presented here have been extracted from the data base of the Utility Acid Precipitation Sampling Program (UAPSP) precipitation chemistry network. These data illustrate the nature of ionic deposition at four points on the eastern seabord. The deposition of $\mathrm{H}^{+}$(acidity) is shown to be dependent upon the amount of sulfate and, to a lesser degree, nitrate in the precipitation. It is also shown that the quantity of ionic deposition on a storm-by-storm basis was influenced by the amount of water deposition but the relationship was not very strong. Thus the use of water deposition as a surrogate for ionic deposition is not justified in these watersheds. Finally, it is shown that the deposition of $\mathrm{H}^{+}, \mathrm{SO}_{4}^{2-}, \mathrm{NO}_{3}^{-}$, and $\mathrm{NH}_{4}^{+}$ were not clearly seasonal. While a large percentage of total ionic deposition occurred in a small number of precipitation events, these exceptional events were not confined to a particular season.
\end{abstract}

\section{Introduction}

The input of ionic material into a watershed can be estimated by either extrapolating point measurement values or integrating transport and deposition model results. The latter technique is still in its infancy and the models employed have yet to be verified as accurate. Nonetheless these techniques are useful in identifying the regions most likely to have contributed to deposition. This paper, however, focuses on the extrapolation of point measurements to a watershed. Data available from the Utility Acid Precipitation Sampling Program were used to examine the characertistics of ionic deposition to watersheds on the eastern seaboard. Annual average deposition amounts are presented for four sites with drainage into east coast estuaries. Additional analysis of other UAPSP sites has been performed by Samson and Moody (1986).

\section{Precipitation Chemistry Data}

The Utility Acid Precipitation Study Program (UAPSP), having continued and expanded a monitoring network established during the Electric Power Research Institute (EPRI) Sulfate Regional Experiment, provided a high quality, long-term chemical data base for this application. The UAPSP is a monitoring program developed under the guidance of EPRI to collect and analyze daily precipitation samples in the eastern United States. Details of the UAPSP sampling and analysis program may be found in the UAPSP annual summary report (1984). Figure 1 shows the location of 


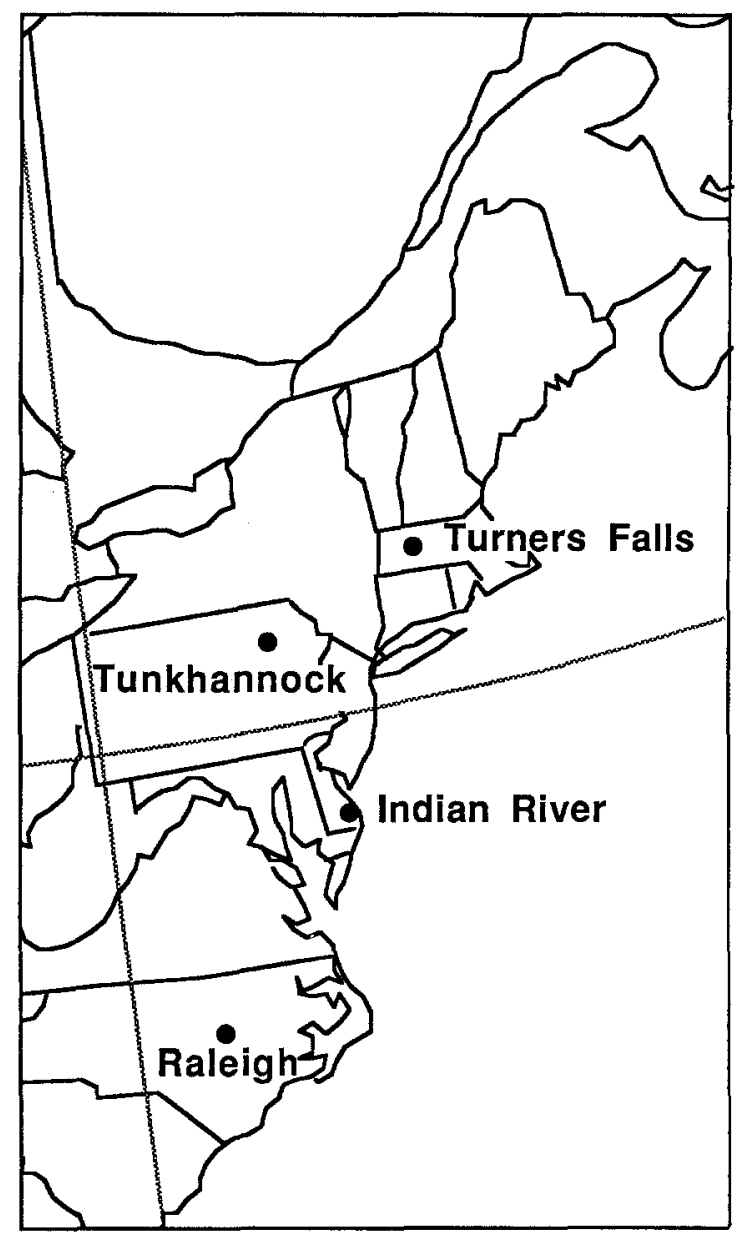

Fig. 1. Location of the Utility Acid Precipitation Study Program Precipitation Chemistry Sampling Network.

TABLE I

Name and location of the utility acid precipitation study program precipitation chemistry sites

\begin{tabular}{llll}
\hline Site & Location & Latitude & Longitude \\
\hline 1 & Turners Falls, Massachusetts & $42^{\circ} 59^{\prime}$ & $72^{\circ} 55^{\prime}$ \\
2 & Tunkhannock, Pennsylvania & $41^{\circ} 35^{\prime}$ & $76^{\circ} 00^{\prime}$ \\
3 & Indian River, Delaware & $38^{\circ} 35^{\prime}$ & $75^{\circ} 15^{\prime}$ \\
8 & Raleigh, North Carolina & $35^{\circ} 44^{\prime}$ & $78^{\circ} 41^{\prime}$ \\
\hline
\end{tabular}


UAPSP sampling stations used in this study. Table I lists the number and location of the sites.

The UAPSP data base provides users with information which includes: (1) the day and hour the first precipitation started and the day and hour the last precipitation ended; (2) the precipitation amount; and (3) a thorough chemical analysis of the major ionic species in solution. The only meteorological information included in the data set was in the form of sample codes which were used to differentiate events as (1) snow/ice events, (2) mixed (liquid and solid sample) events or hail events, (3) uncoded events (indicating precipitation fell as rain), and (4) events with thunder. This information was used to determine the influence of precipitation type on ionic concentrations.

The four sites investigated in this work include: Site 1, Turners Falls, Massachusetts; Site 2, Tunkhannock, Pennsylvania; Site 3, Indian River, Delaware; and Site 8, Raleigh, North Carolina. Deposition at these sites should be representative of atmospheric input into the upper Connecticut River, the upper Susquehanna River, the Delaware/Chesapeake Bay region, and the North Carolina coastal plains, respectively. Clearly large variations in deposition are possible across a watershed due to variations in precipitation amount and air quality. These sites are presented only to illustrate the nature of deposition in these regions.

\section{Results}

The deposition of $\mathrm{H}^{+}$is dependent upon the amount of anions available in the precipitation. At the eastern seaboard sites the $\mathrm{H}^{+}$is largely dependent upon sulfate $\left(\mathrm{SO}_{4}^{2-}\right)$ and nitrate $\left(\mathrm{NO}_{3}^{-}\right)$. Figures 2(a) and 2(b) compare the 1979 concentrations* of $\mathrm{SO}_{4}^{2-}$ and $\mathrm{H}^{+}$and $\mathrm{NO}_{3}^{-}$and $\mathrm{H}^{+}$, respectively, at the Indian River site. There was a strong linear correlation between $\mathrm{SO}_{4}^{2-}$ and $\mathrm{H}^{+}$with a ratio of $\mathrm{H}^{+} / \mathrm{SO}_{4}^{2-}$ which was slightly greater than one. The $\mathrm{H}^{+}$concentrations were also related to $\mathrm{NO}_{3}^{-}$concentrations but the ratio approached two to one.

The amount of ionic material deposited in a storm should intuitively be related to the amount of water being deposited. Figure 3(a) shows, however, that day-by-day $\mathrm{SO}_{4}^{2-}$ deposition was only weakly related to the concurrent water deposition. This lack of correlation was the result of fluctuations in the concentration of $\mathrm{SO}_{4}^{2-}$ in precipitation. Such fluctuations are expected due to varying concentrations of atmospheric $\mathrm{SO}_{2}$ and $\mathrm{SO}_{4}^{2-}$. The $\mathrm{SO}_{4}^{2-}$ concentration in precipitation has been shown to vary seasonally (cf. Wilson et al., 1980). This alone could lead to poor correlation between day-by-day water and $\mathrm{SO}_{4}^{2-}$ deposition over the course of a year. On the other hand, Figure 3(b) compares $\mathrm{NO}_{3}^{-}$deposition with water deposition and finds a similar lack of correlation even though $\mathrm{NO}_{3}^{-}$does not display a seasonal oscillation in concentration. Hence, the poor correlation between water deposition and ionic deposition must be the result of

\footnotetext{
* Ionic concentration is expressed as mass per unit volume of water, whereas ionic deposition is expressed in units of mass per area. Concentration comparisons will be used here when discussing processes but depositions wil be cited when discussing input to watersheds.
} 


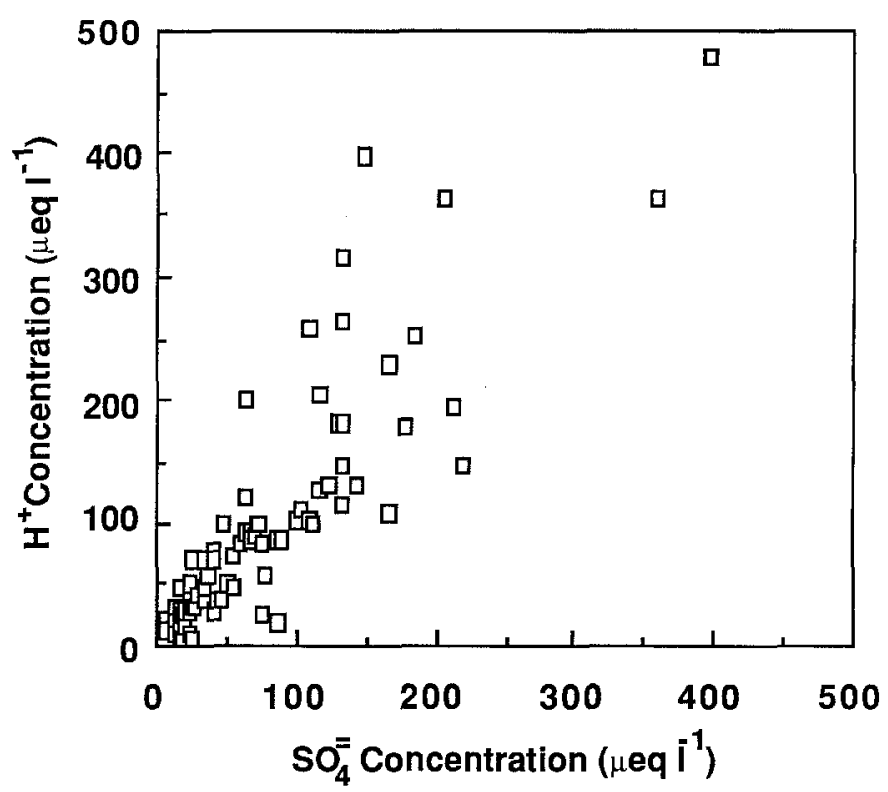

Fig. 2a. Comparison of the concentration of $\mathrm{H}^{+}$and $\mathrm{SO}_{4}^{2-}$ in precipitation events recorded during 1979 at the Indian River, Delaware UAPSP site.

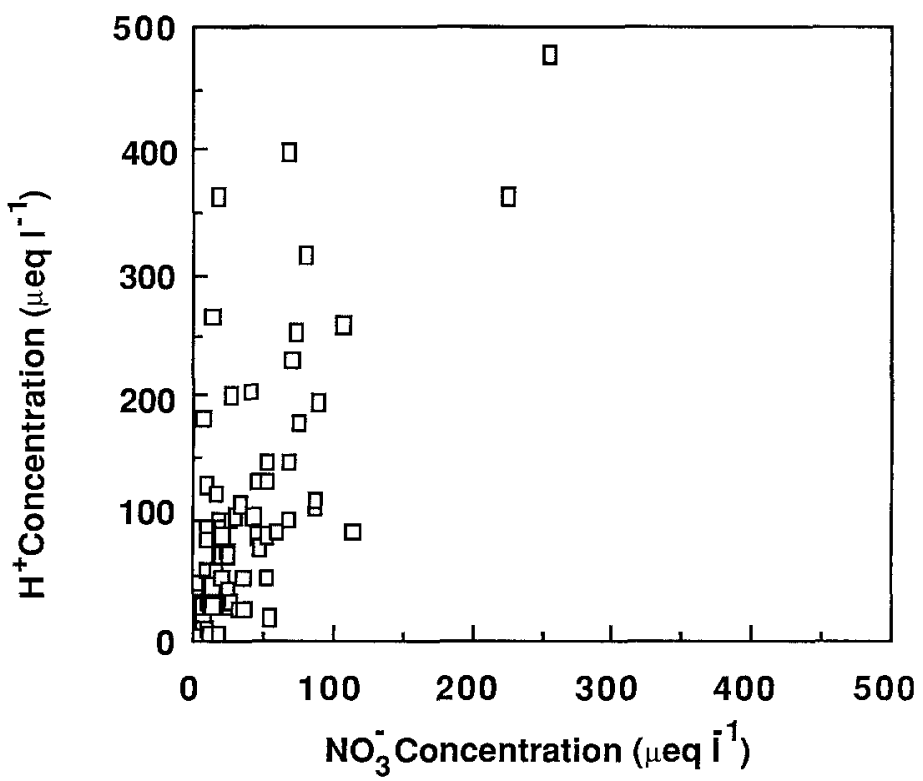

Fig. 2b. Comparison of the concentration of $\mathrm{H}^{+}$and $\mathrm{NO}_{3}^{-}$in precipiration events recorded during 1979 at the Indian River, Delaware UAPSP site. 


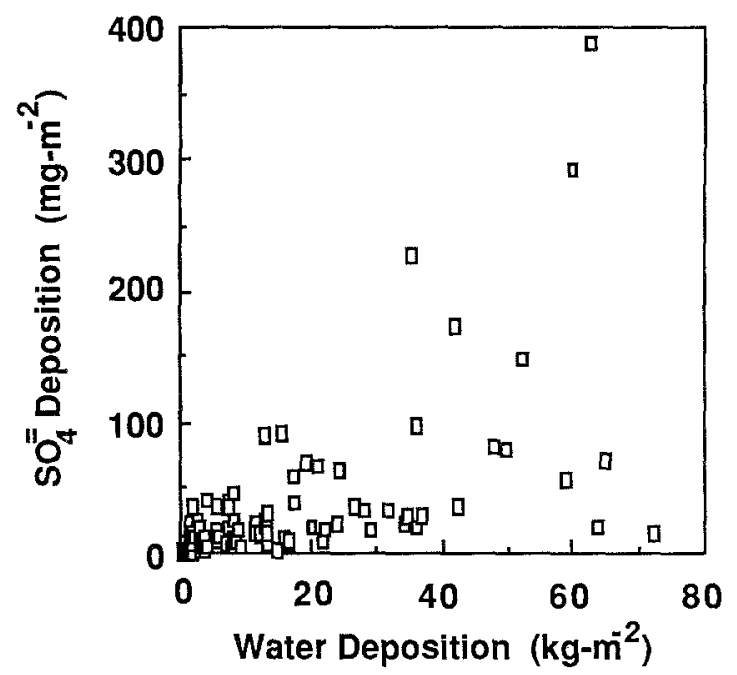

Fig. 3a. Comparison of the deposition of $\mathrm{SO}_{4}^{2-}$ and water in precipitation events recorded during 1979 at the Indian River, Delaware UAPSP site.

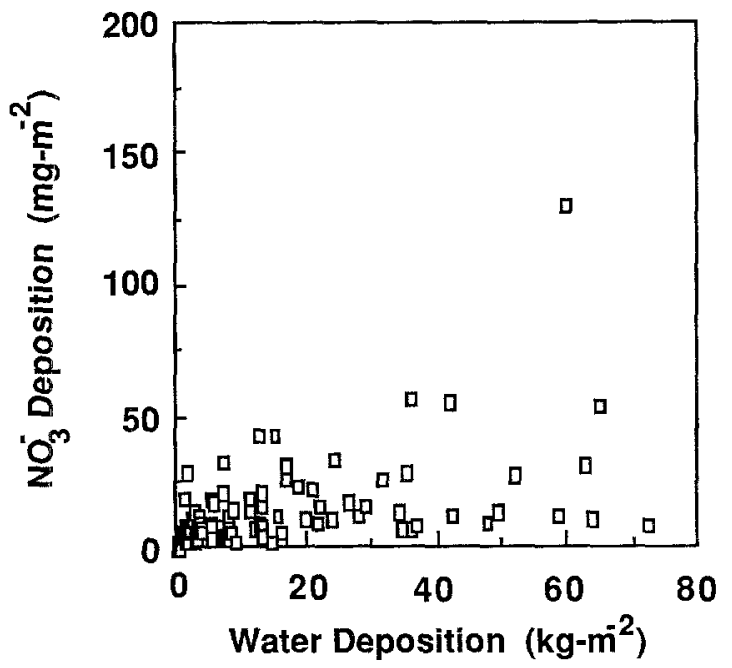

Fig. 3b. Comparison of the deposition of $\mathrm{NO}_{3}^{-}$and water in precipitation events recorded during 1979 at the Indian River, Delaware UAPSP site.

the changing cloud and pollutant environment on a day-by-day basis. Moreover, this demonstrates that water deposition was a poor surrogate for ionic deposition at these sites.

The deposition of ions into a watershed via precipitation is an intermittent process with the bulk of the annual deposition occurring in a few major events. Figure 4 shows 


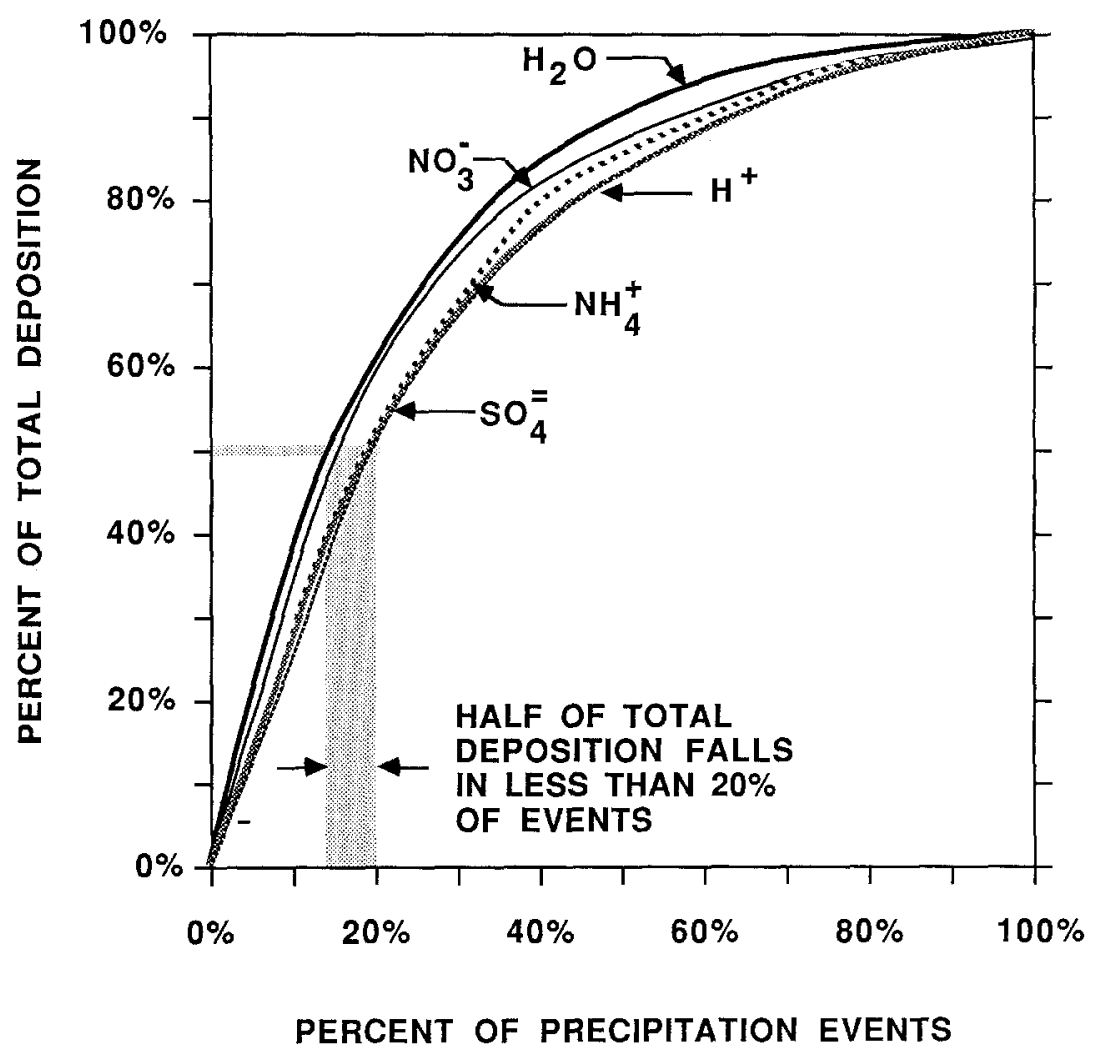

Fig. 4. The cumulative frequency of deposition of $\mathrm{H}^{+}, \mathrm{SO}_{4}^{2-}, \mathrm{NO}_{3}^{-}, \mathrm{NH}_{4}^{+}$, and water over the year 1979 at the Indian River, Delaware UAPSP site.

TABLE II

Annual deposition totals for four UAPSP sites in eastern seaboard watersheds

\begin{tabular}{lccllll}
\hline Site & Year & $\begin{array}{l}\text { Water } \\
\left(\mathrm{kg} \mathrm{m}^{-2}\right)\end{array}$ & $\begin{array}{l}\mathrm{H}^{+} \\
\left(\mathrm{kg} \mathrm{ha}^{-1}\right)\end{array}$ & $\begin{array}{l}\mathrm{SO}_{4}^{2-} \\
\left(\mathrm{kg} \mathrm{ha}^{-1}\right)\end{array}$ & $\begin{array}{l}\mathrm{NO}_{3}^{-} \\
\left(\mathrm{kg} \mathrm{ha}^{-1}\right)\end{array}$ & $\begin{array}{l}\mathrm{NH}_{4}^{+} \\
\left(\mathrm{kg} \mathrm{ha}^{-1}\right)\end{array}$ \\
\hline Turners Falls, Massachusetts & 1982 & 1017 & 0.5 & 22.6 & 15.0 & 2.1 \\
& 1983 & 1455 & 0.6 & 25.3 & 16.5 & 2.3 \\
Tunkhannock, Pennsylvania & 1979 & 823 & 0.6 & 21.4 & 13.5 & 1.7 \\
& 1980 & 642 & 0.6 & 16.7 & 11.1 & 1.6 \\
& 1982 & 676 & 0.5 & 18.5 & 11.4 & 2.0 \\
Indian River, Delaware & 1983 & 1113 & 0.8 & 20.5 & 13.9 & 1.7 \\
Raleigh, North Carolina & 1979 & 1573 & 0.9 & 33.6 & 13.2 & 4.2 \\
& 1979 & 1256 & 0.4 & 15.7 & 8.6 & 3.6 \\
& 1980 & 941 & 0.4 & 16.8 & 10.0 & 2.2 \\
& 1981 & 808 & 0.3 & 12.3 & 6.8 & 1.4 \\
& 1982 & 1147 & 0.5 & 20.4 & 10.7 & 2.7 \\
& 1983 & 1259 & 0.4 & 19.5 & 11.0 & 3.0 \\
\hline
\end{tabular}


TABLE III

Deposition totals for the period March to May for four UAPSP sites in eastern seaboard watersheds

\begin{tabular}{lcccccc}
\hline Site & Year & $\begin{array}{l}\text { Water } \\
\left(\mathrm{kg} \mathrm{m}^{-2}\right)\end{array}$ & $\begin{array}{l}\mathrm{H}^{+} \\
\left(\mathrm{kg} \mathrm{ha}^{-1}\right)\end{array}$ & $\begin{array}{l}\mathrm{SO}_{4}^{2-} \\
\left(\mathrm{kg} \mathrm{ha}^{-1}\right)\end{array}$ & $\begin{array}{l}\mathrm{NO}_{3}^{-} \\
\left(\mathrm{kg} \mathrm{ha}^{-1}\right)\end{array}$ & $\begin{array}{l}\mathrm{NH}_{4}^{+} \\
\left(\mathrm{kg} \mathrm{ha}^{-1}\right)\end{array}$ \\
\hline Turners Falls, Massachusetts & 1982 & 262 & 0.1 & 4.2 & 3.0 & 0.4 \\
& 1983 & 523 & 0.2 & 10.5 & 7.0 & 1.0 \\
Tunkhannock, Pennsylvania & 1979 & 235 & 0.2 & 7.2 & .4 .6 & 0.6 \\
& 1980 & 256 & 0.1 & 5.0 & 4.0 & 0.5 \\
& 1982 & 208 & 0.1 & 6.3 & 4.2 & 0.9 \\
Indian River, Delaware & 1983 & 394 & 0.4 & 6.6 & 4.3 & 0.6 \\
& 1979 & 351 & 0.1 & 5.2 & 2.9 & 1.0 \\
Raleigh, North Carolina & 1980 & 340 & 0.2 & 7.0 & 3.4 & 1.1 \\
& 1979 & 370 & 0.1 & 4.7 & 2.9 & 1.2 \\
& 1980 & 291 & 0.1 & 4.0 & 2.2 & 0.6 \\
& 1981 & 131 & 0.1 & 2.8 & 1.5 & 0.3 \\
& 1982 & 263 & 0.1 & 5.5 & 3.3 & 0.8 \\
\hline
\end{tabular}

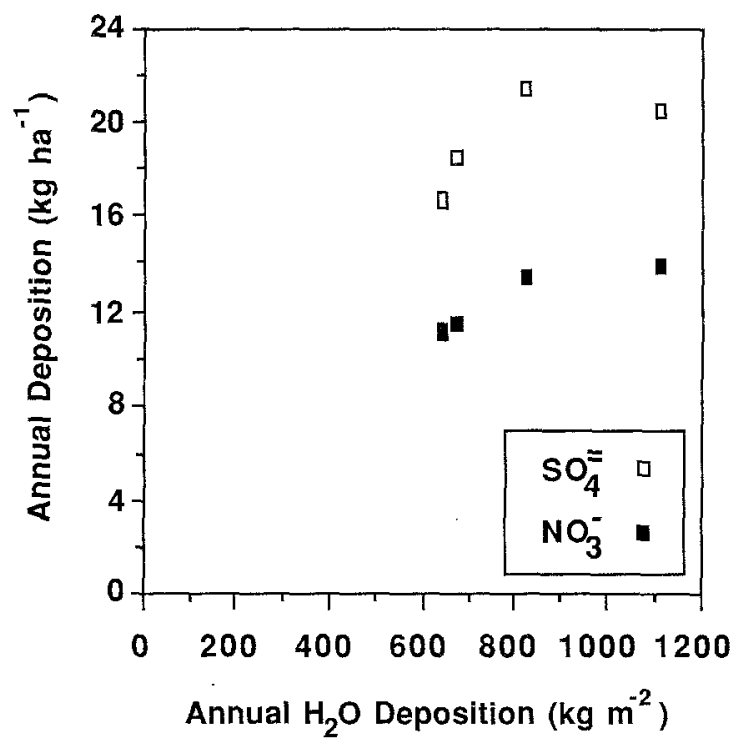

Fig. 5. A scatter plot of annual deposition of $\mathrm{SO}_{4}^{2-}$ and $\mathrm{NO}_{3}^{-}$versus total water deposition for four years at Tunkhannock, Pennsylvania.

the cumulative frequency distribution for deposition of water, $\mathrm{H}^{+}, \mathrm{SO}_{4}^{2-}, \mathrm{NO}_{3}^{-}$, and $\mathrm{NH}_{4}^{+}$at the Indian River, Delaware UAPSP site. This plot shows that $50 \%$ of the total deposition of all species occurred in only about $20 \%$ of the precipitation events. Moreover, about $90 \%$ of the total annual deposition was accounted for by only half of 


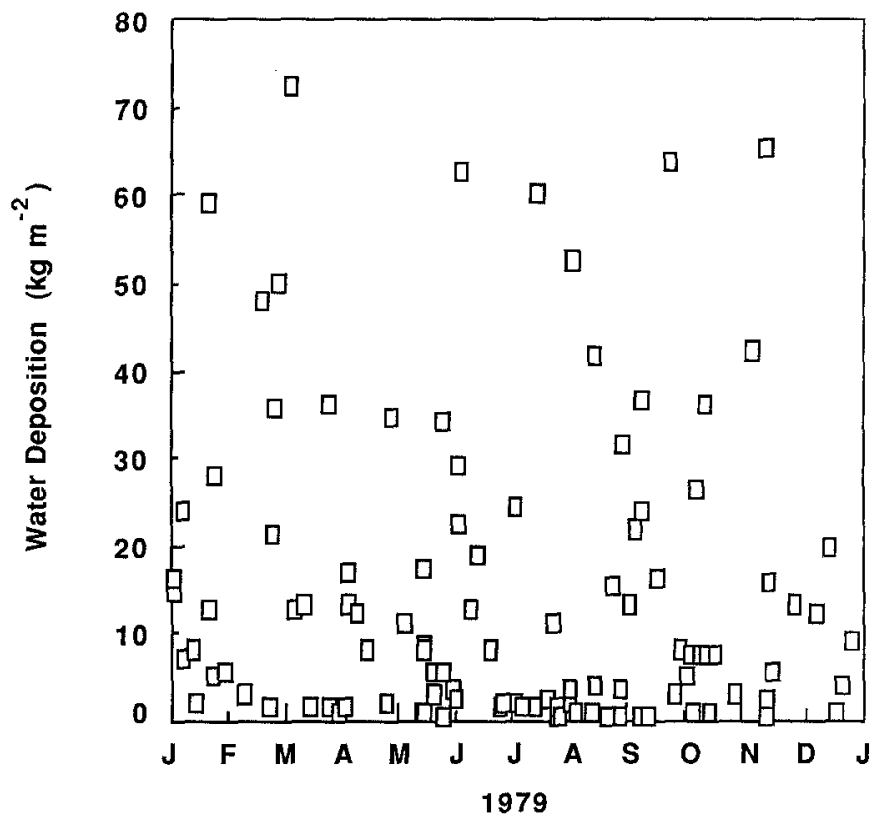

Fig. 6a. The amount of deposited water in each precipitation event measured at the UAPSP site in Indian River, Delaware during 1979.

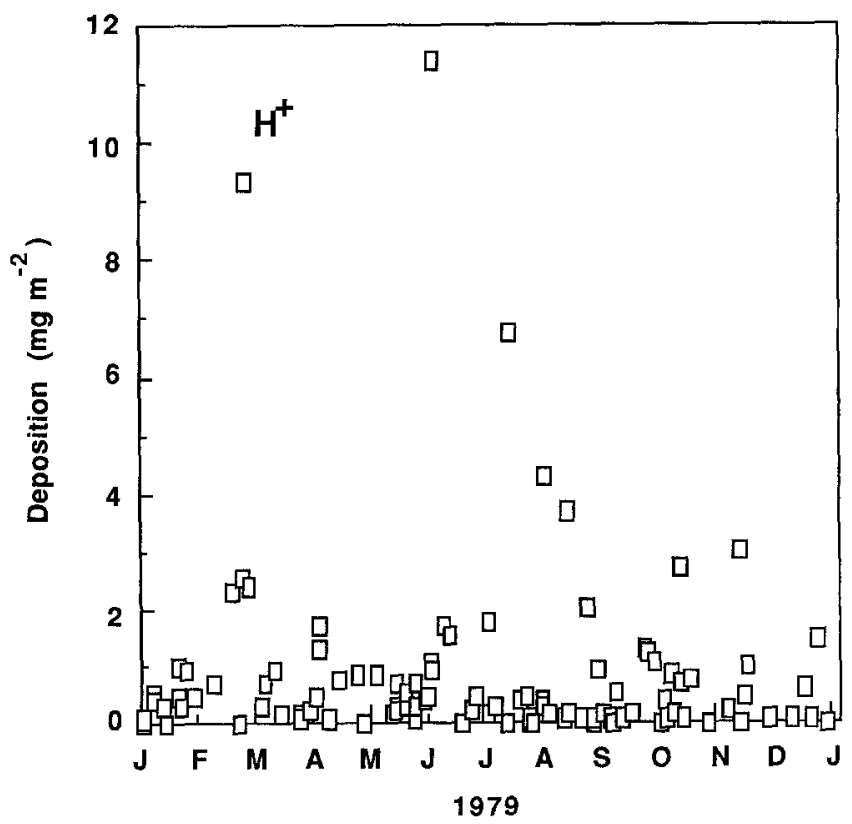

Fig. $6 \mathrm{~b}$. The amount of deposited $\mathrm{H}^{+}$in each precipitation event measured at the UAPSP site in Indian River, Delaware during 1979. 


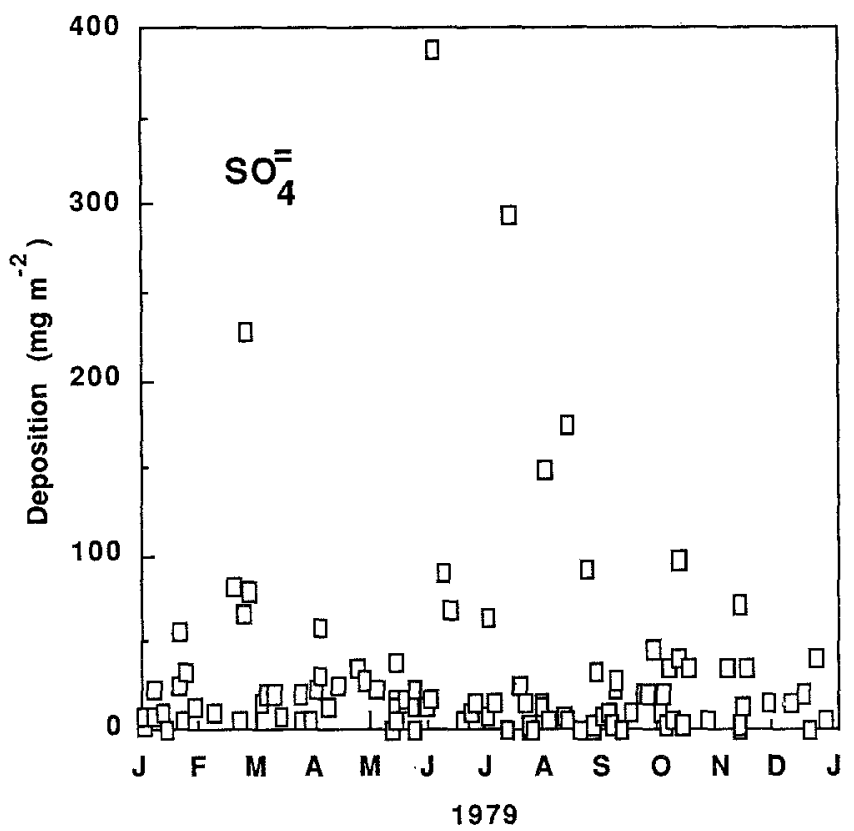

Fig. 6c. The amount of deposited $\mathrm{SO}_{4}^{2-}$ in each precipitation event measured at the UAPSP site in Indian River, Delaware during 1979.

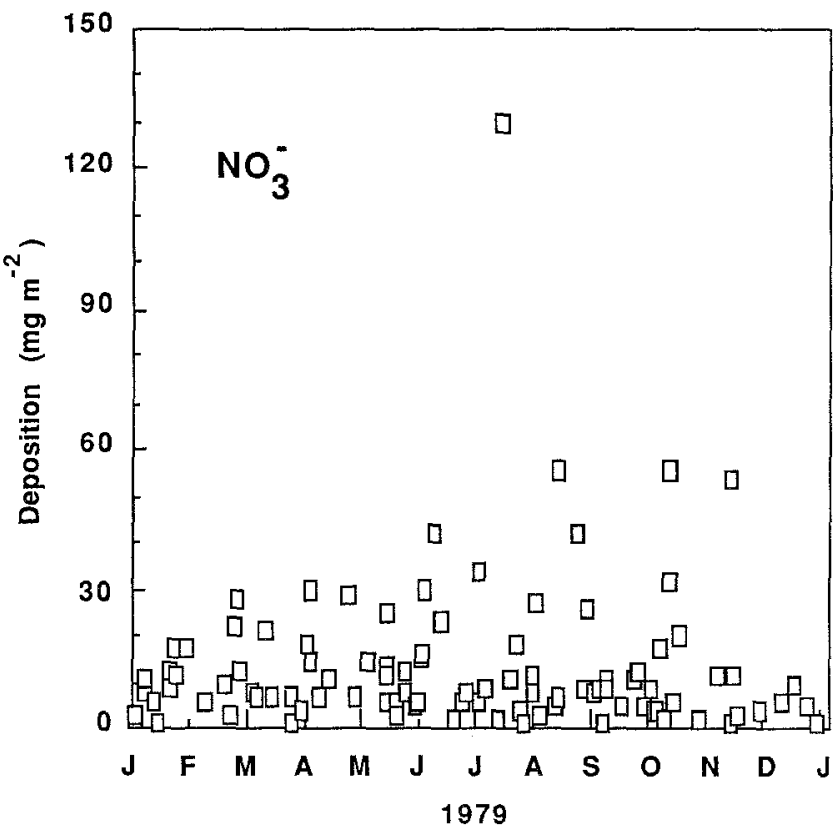

Fig. 6d. The amount of deposited $\mathrm{NO}_{3}^{-}$in each precipitation event measured at the UAPSP site in Indian River, Delaware during 1979. 


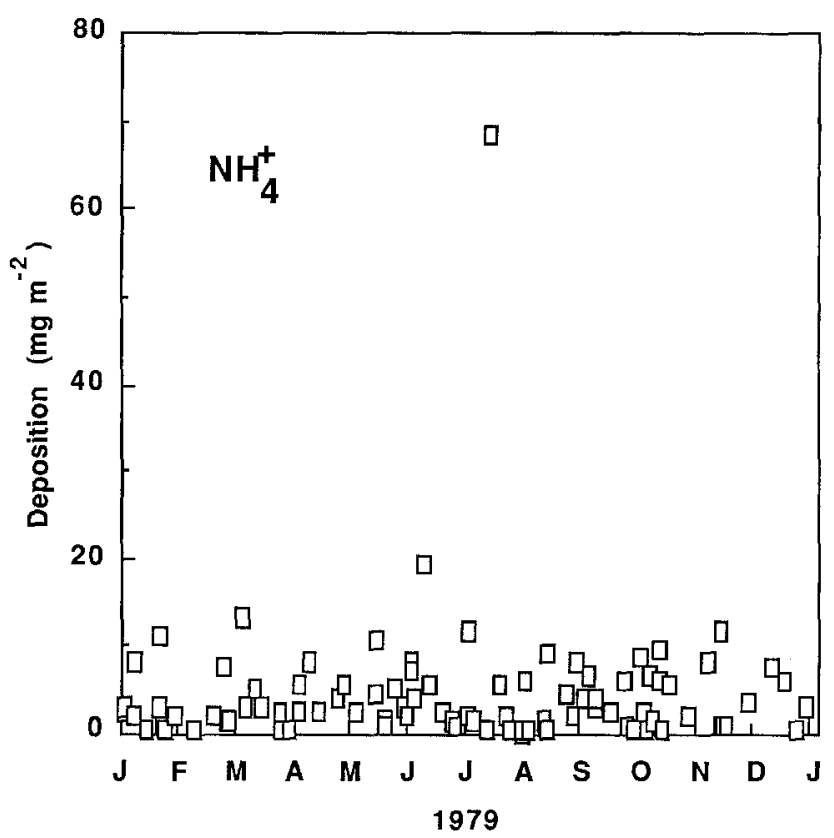

Fig. 6e. The amount of deposited $\mathrm{NH}_{4}^{+}$in each precipitation event measured at the UAPSP site in Indian River, Delaware during 1979.

the precipitation events in the year. Thus the influence of ionic deposition on the chemistry in precipitation and hence in streams was generally dominated by extreme events. In northern regions, however, it is possible that the accumulation from several storms in snowpack could also have caused significant changes in stream chemistry during melting periods. This is not addressed in this paper.

The annual deposition amounts of $\mathrm{H}^{+}, \mathrm{SO}_{4}^{2-}, \mathrm{NO}_{3}^{-}, \mathrm{NH}_{4}^{+}$, and water at the four sites are listed in Table II. The amount of deposition varied from site-to-site and year-to-year. Note, for example, that 1983 exhibited relatively high deposition of ionic material at each of the available sites due in large part to the greater deposition of water. The Delaware site exhibited the highest deposition of $\mathrm{H}^{+}$and $\mathrm{SO}_{4}^{2-}$ of the four sites but this was based on only one year of data. The variations in deposition amounts when the data were stratified by spawning season did not mirror the annual results. Table III lists the amount of deposition during the warming months (assumed to be March to May) when anadromous fish were presumably spawning in these watersheds.

While the number of years of deposition measurements in the eastern seaboard area were limited, the data showed that variations in annual ionic deposition have not been linearly related to variations in annual water deposition. Figure 5 shows a plot of $\mathrm{SO}_{4}^{2-}$ and $\mathrm{NO}_{3}^{-}$deposition versus the total water accumulation for each year at the Tunkhannock, Pennsylvania site. The irregularity of the scatter implies that it is not reliable to infer variations in even annual ionic deposition based on the fluctuations of annual precipitation amount. 
The variations in deposition of $\mathrm{H}^{+}, \mathrm{SO}_{4}^{2-}, \mathrm{NO}_{3}^{-}, \mathrm{NH}_{4}^{+}$, and water over the course of the year are displayed in Figures 6(a) through 6(e), respectively. All ions showed considerable variability over the course of the year with no consistent seasonal trend evident. Only $\mathrm{SO}_{4}^{2-}$ exhibited any seasonal oscillation as a result of a few high deposition events in the warmer months. Nonetheless, the probability of high deposition values was similar in virtually all months.

\section{Discussion}

The deposition of $\mathrm{H}^{+}$has been shown to be dependent upon the amount of sulfate and, to a lesser degree, nitrate in the precipitation. This relationship has been demonstrated to be true for most measurements sites in the eastern United States (Samson and Moody, 1986) and is not surprising. It has also shown that the quantity of ionic deposition on a storm-by-storm basis was influenced by the amount of water deposition but the relationship was not very strong. The variations in ionic deposition were due to variations in concentration. Even the annual deposition totals showed little relationship between total water deposition and the total deposition of $\mathrm{SO}_{4}^{2-}$ and $\mathrm{NO}_{3}^{-}$. Hence, the use of annual precipitation amount to infer variations in ionic deposition is not justified.

The deposition of ionic material (and water, for that matter) was highly weighted towards a few 'exceptional' events during the year. Further, these high deposition events occurred in any season in the eastern seaboard region of the United States. The year-to-year variations in deposition amount during 'spawning season' were relatively large. The relationship of these fluctuations to changes in anadromous fish populations remains to be studied.

The extrapolation of ionic deposition measurements to a watershed is probably the most reliable method for estimating atmospheric input of pollutants. Nonetheless, this paper has illustrated how this process has limitations. These limitations include the nonhomogeneity of precipitation patterns across the watershed (cf. Nappo et al., 1980) and nonlinearity between ionic deposition and water deposition.

It will be useful in the future to identify other environmental factors such as extremes in temperature and precipitation to see if these factors can be linked to changing fish populations. The relative importance of climatic factors, pollutant deposition and other processes remains to be identified.

\section{References}

Nappo, C. J. and Gabbard, L. J.: 1980, Monthly Weather Rev. 108, 1579.

Samson, P. J. and Moody, J. L.: 1986, The Influence of Meteorological Factors on Precipitation Chemistry, Report UAPSP-111, Electric Power Research Institute, Palo Alto, CA.

UAPSP Summary Report: 1984, Acid Precipitation Study Program Second Summary Report, Report UAPSP-109, Electric Power Research Institute, Palo Alto, CA.

Wilson, J., Mohnen, V. A., and Kadlecek, J. A.: 1982, Atmos. Environ. 16, 1667. 